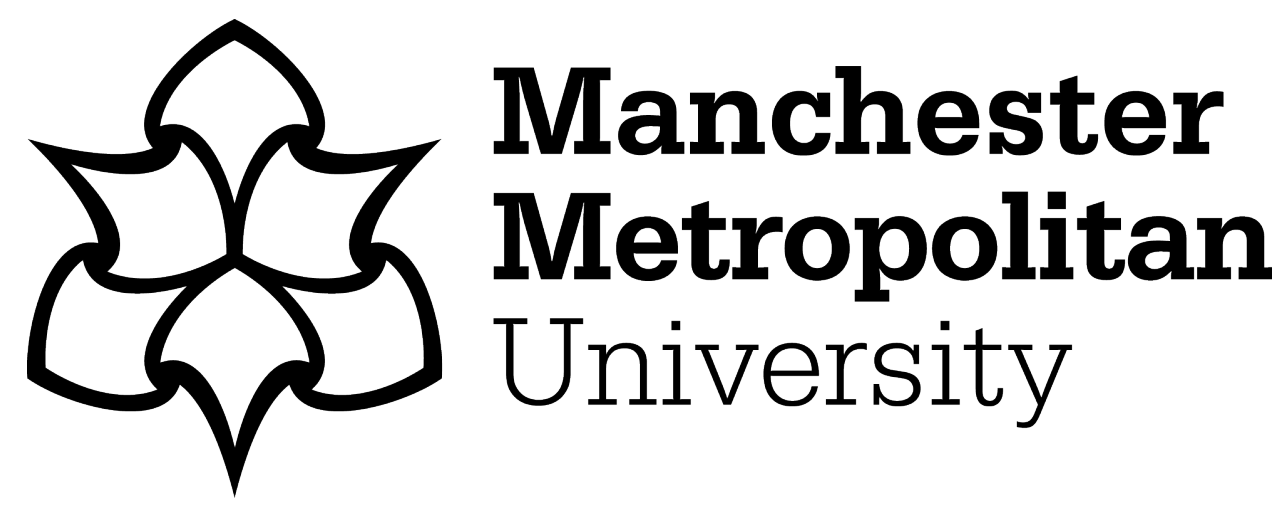

Majeed-Ariss, Rabiya, Brockway, Alice, Cook, Kate ORCID logoORCID: https://orcid.org/0000-0003-1222-1313 and White, Cath (2021) "Could do better": report on the use of special measures in sexual offences cases. Criminology and Criminal Justice, 21 (1). pp. 89-106. ISSN 1748-8958

Downloaded from: https://e-space.mmu.ac.uk/622583/

Version: Accepted Version

Publisher: SAGE Publications

DOI: https://doi.org/10.1177/1748895819840396

Please cite the published version 


\section{"Could do better": Report on the use of special measures in sexual offences cases}

\section{Author Names:}

Rabiya Majeed-Ariss PhD ${ }^{\text {ab }}$, Alice Brockway ${ }^{\mathrm{a}}$, Kate Cook $^{\mathrm{c}}$ and Catherine White ${ }^{* a}$ FRCOG, FFFLM, MRCGP

${ }^{a}$ Manchester University Hospitals NHS Foundation Trust, UK

${ }^{\mathrm{b}}$ University of Manchester, School of Health Sciences, UK

c Manchester Metropolitan University, Manchester Law School, UK

*Corresponding Author: Dr Catherine White, Clinical Director

Address: Saint Mary's Sexual Assault Referral Centre, York Place, Oxford Road, Manchester, M13 9WL.

Tel: 01612766515

Fax: 01612766028

E-mail: Cath.White@mft.nhs.uk 


\section{Author Biographies:}

Dr. Rabiya Majeed-Ariss is the Research Associate working at Saint Mary's Sexual Assault Referral Centre since 2015. In her role, Rabiya has developed research-based knowledge to promote more evidence-based practice at the Centre.

Rabiya.Majeed@mft.nhs.uk 01612766515

Ms. Alice Brockway is an early-stage researcher. She is currently working on her PhD, which looks at mental health disability in professional actors, at Manchester Metropolitan University.

\section{Alice.Brockway@mft.nhs.uk}

Dr. Kate Cook is a Senior lecturer in law at Manchester Law School. Kate is also the Head of the Sylvia Pankhurst Gender and Diversity Research Centre at Manchester Metropolitan University.

k.cook@mmu.ac.uk (0161) 2472799

Dr Catherine White OBE has been the Clinical Director of Saint Mary's Sexual Assault Referral Centre since 2003 having started as one of the forensic physicians in 1995. Catherine is a UN consultant on Sexual Violence and was Vice President for the Faculty of Forensic and Legal Medicine 2010-2013.

Cath.White@mft.nhs.uk 01612766515 


\section{Abstract}

This article reports on research into the use of "special measures" in sexual offence cases. It begins by outlining the background: considering the perennial problem of attrition within the criminal justice system; explaining why special measures are considered important and outlining the rules surrounding their use. The next step is to explain the research and then the discussion turns to the results so far. This study surveyed 61 sexual offence complainants on how they had decided to give evidence in court and what influenced this decision. This is the first time a team has evaluated special measures including the remote live link, from the point of view of the complainants. The complainant's descriptions of their choices were analysed to identify key themes, which are presented here. The results highlight that there are some problems with the practical implementation of these measures, particularly given the views of the complainants.

Keywords Special Measures; Sexual Offences; Live Link Evidence; Complainant Visibility

Final word count 7982 words

\section{Introduction}

The Saint Mary's Sexual Assault Referral Centre (SARC) in Manchester was the first of its kind in the country and remains at the forefront in developing ways of working with those reporting sexual offences. Since 2016 Saint Mary's SARC has had a remote live link, which allows complainants to give their evidence from the familiar surroundings of the Centre, rather than having to go to court. This study started out with the aim of evaluating the usefulness of this Live Link. However, the research team realised that it made more sense to consider the range of special measures and this article provides an early insight into the results. The team have been somewhat surprised to discover differences between the legal rules on special measures and what actually gets offered to complainants heading for court. The study therefore reveals some issues with the implementation of special measures locally. These concern the ways that decisions about special measures are made; refusal of the use of a combination of special measures and limitations on the circumstances whereby a support worker can be present, whilst evidence is given. 
The article begins by introducing the rules on special measures, considering the reasons for their development and the long-term problem of attrition in this type of prosecution. Following on, the existing research into special measures is reviewed, showing that this is a novel study, in terms of scope and method. The discussion moves on to outline the work of the Saint Mary's SARC and the way the staff there have facilitated this piece of research. The research method is presented next, followed by the results to date. The sample considered here looks at the views of 61 complainants in sexual offences cases with regards to special measures and at the choices they made, when going to court. Their words are used to illustrate the themes coming from the work to date: visibility; in the courtroom; use of live links and other influences. Finally, some conclusions and notes of future research aims are recorded.

\section{Background}

Sexual offences are very serious crimes, which cause distress and harm to those victimised, some of which can be lifelong (Jones and Cook, 2008). These crimes deserve the best responses from the Criminal Justice System (CJS), but there are ongoing and persistent concerns about a number of aspects of the CJS response and, in particular, about the conviction rates (Cook, 2011). The most recently published set of statistics show that 36,655 rapes of females and 4,531 rapes of males were reported to the police and recorded as crimes, during the year ended March 2017 (Sexual Offences Appendix tables, 2018). Ministry of Justice statistics suggest that only 1128 convictions for rape were achieved in the year to December 2017 (UK Government, 2017). Clearly these reported figures do not relate to the same datasets. Nevertheless, they give a very poor account of the performance of the CJS in convicting accused rapists and show the ongoing issue of attrition in rape cases very starkly. At present a very small minority of reported rape cases results in conviction. There are many factors that contribute to this and the remainder of this article focuses on just one aspect of the cases that get as far as court (acknowledging that many drop out long before that point) (Cook, 2011).

It is not uncommon for complainants in criminal cases and particularly in sexual offence cases, to experience anxiety and fear during the investigation of a crime and in particular, when attending court and giving evidence. Stress can affect the quantity and quality of complainant communication. Some complainants may have particular difficulties attending court and/or giving evidence due to their personal circumstances or 
particular needs. In such cases, where complainants are considered to be vulnerable or intimidated, the court considers it crucial to improve the quality of their experience to help them give their "best evidence".

The Youth Justice and Criminal Evidence Act 1999 (YJCEA) introduced a series of provisions that can be used to facilitate the gathering and giving of evidence by vulnerable and intimidated witnesses, these measures are collectively known as "special measures". Special measures are known to relieve some of the stress associated with giving evidence and thereby help witnesses give their best evidence in court. While there has been consideration given to extending special measures to the defendant (Fairclough, 2018) currently special measures apply only to prosecution and defence witnesses and are subject to the discretion of the court (YJCEA, ss.16-33). Under YJCEA s. 17(4), there is automatic eligibility for special measures where the witness is a complainant of a sexual offence, unless the complainant has informed the court that they do not wish to be eligible.

YJCEA Sections 23 to 30 provide details of the special measures which may be used by complainants of sexual offences (current rules can also be found at: Special Measures / The Crown Prosecution Service, 2017):

- Video- recorded interviews may be admitted by the court as the complainant's evidence-in-chief in sexual offences trials in the crown court. Video-recorded cross-examination and re-examination are also possible (YJCEA s.27).

- Pre-recording of cross-examination and re-examination of the complainant will be done via the live link from the court room to the complainant suite and the examination will be recorded (YJCEA s.28). The judge and legal representatives must be able to see and hear the complainant' examination and communicate with the person in whose presence the recording is being made. The accused must also be able to see and hear the examination and to communicate with his legal representative. That said, it is possible for the complainant to be screened if required.

- Screens are available to shield the complainant from the defendant and the public gallery whilst they are in the courtroom. Although these were available before the Act, the literature suggests that they were not often used (Hamlyn, B. et al 2004). YJCEA, s.23 states that the screen must not prevent the complainant from seeing and being seen by the judge, the jury, legal representatives acting in the proceedings and any interpreters appointed. Giving evidence through the use of screens is 
particularly useful where complainants are distressed by the prospect of being seen by the defendant or of having to see the defendant again.

- $\quad$ Removing wigs and gowns only applies to proceedings in the Crown Court (YJCEA s.26). This special measure is more likely to be used in cases which involve children giving evidence. An impact of removing the wigs and gowns is that it produces a less formal situation.

- Giving evidence in private, excluding members of the public, is another special measure in cases of sexual offences. However, individuals who should not be excluded from the courtroom include the accused, legal representatives acting in the proceedings and any interpreters required to assist complainants (YJCEA s.25).

- Communications aids enable a complainant to give best evidence whether through a communicator or interpreter (YJCEA s.30).

- Registered intermediaries facilitate as complete and accurate two-way communication between the vulnerable complainant and the other participants in the legal process as possible (YJCEA s.29). The intermediary provides the court with an assessment of the communication difficulties faced by the complainant and advises how to achieve the best evidence from the complainant. The intermediary first attends a ground rules hearing before the trial takes place to determine what role they will play in the case and to advise the court on the form of questioning they should and should not use during the trial.

Sections 51 of the Criminal Justice Act 2003 introduced another special measure

- Live link TV (sometimes known as "videolink") enables the complainant to give evidence during the trial from outside the courtroom through a televised link. The complainant may be situated in another room within the court building itself or in a suitable location outside the court.

The Crown Prosecution Service (CPS) website also specifically comments that: "A combination of special measures may be appropriate. For example, if a complainant who is to give evidence by live link wishes, screens can be used to shield the live link screen from the defendant and the public, as would occur if screens were being used for a complainant giving evidence in the court room." (Special Measures / The Crown 
Prosecution Service, 2017) However this study has highlighted that this is not being permitted, in practice, in the Manchester courts. This issue is discussed further below.

In addition to these special measures the CJS should offer pre-trial visits so that complainants can attend the court prior to the trial to familiarise themselves with the layout and minimise anxiety. The previous research on the effectiveness of special measures suggest that in general, these measures appear to be worthwhile, in terms of reducing the anxiety of vulnerable and intimidated complainants in general and those in sexual offences cases, in particular.

The needs of the complainant should be identified and considered by the police at the charging stage and throughout the duration of the case. A prescribed form (Form MG2) is often used by police to do this and it is passed on to the CPS. Police and CPS should discuss, with the complainant or with the complainant's carer, the special measures that are available and the complainant's needs, such that the most appropriate package of special measures can be identified. The CPS prosecutor should then consider applying for special measures to help complainants give their best evidence in court.

The overriding objective is that all criminal cases must be dealt with justly and this includes respecting the interests of complainants. The objective also ensures that cases are dealt with efficiently and as quickly as possible. This means the courts must actively manage the case, identifying the needs of the complainant at an appropriate stage in proceedings.

The court can exercise its powers to give, vary or discharge a special measures direction either at a hearing, whether in public or in private, or without a hearing. This means that the court has discretion when deciding to allow, change or deny a special measures direction. Decisions are made with maximising the quality of the complainant's evidence in mind.

What does existing literature tell us about impact of special measures? 
In the Home Office's research (Hamlyn, B. et al, 2004), surveys were completed with over 1000 vulnerable and intimidated witnesses, of these $15 \%$ were victims of sexual offences. The surveys were used to determine whether special measures influenced vulnerable and intimidated witnesses satisfaction levels. Witnesses using the special measures reported feeling less anxious and less intimidated and generally more satisfied than those not using special measures. A third of witnesses reported feeling unwilling or unable to give evidence without special measures emphasising their importance. The report concluded while special measures have improved satisfaction there is still more work to be done with service provision as anxiety remains high amongst vulnerable and intimidated witnesses. Hall (2007) warned against treating special measures with a one-size-fits-all perspective noting that while video links are beneficial for some witnesses for others they can be detrimental. These pieces of work show that a range of choices are important for witnesses.

Existing research has also investigated the impact of special measures on jury decision-making, using mock trials (Ellison \& Munro, 2014). It was found that three different modes of presentation (1, live links; 2, videorecorded evidence-in-chief followed by live link cross-examination and 3, protective screens) had no clear or consistent impact on mock jury's deliberations when considering testimonies of adult rape.

There is relatively little research into the use of remote live links (such as the one at the Saint Mary's SARC). However, a small evaluation in Northern Ireland reviewed remote live link facilities in relation to evidence given by children (McNamee et al., 2012). This study undertook qualitative interviews or focus groups with key stakeholders but did not include young complainants themselves. The evaluation found the remote live link supported young people in giving their best evidence because they felt themselves to be in a safe and secure environment and consequently experienced less stress.

Another Home Office report (Burton et al., 2006) evaluated the effectiveness of criminal justice agencies in implementing special measures through interviews with complainants and professionals in the legal system. The team found pre-court visits were not always offered to vulnerable and intimidated complainants and this perpetuated the problem of inaccurate information from the police about available special measures. Another finding was that the CPS commonly applied for special measures at a late stage, including on the day of the trial. While this was accepted practice in relation to particular measures e.g. use of screens, removal of wigs and gowns, it ignored the value to complainants being mentally prepared for what will happen in court. The 
report concluded several areas of practice required improvement which could be achieved through cultural, legislative and structural change.

More research is required on what drives and influences choice of special measures amongst witnesses. The aim of the current project is to evaluate what special measures are available to adult complainants in sexual offence cases, which special measures they choose and why i.e. what influences complainants decisions. The objective of this project was to investigate views of complainants regarding reasons for choosing their preferred special measure(s) and their ideas on improvements that may be made around special measures. This study is innovative in reviewing the entire range of special measures and doing so from the perspective of the complainants themselves. It is novel in that the use of remote live links in England has not yet been evaluated and the perspective of adult complainants is often missing from the literature.

\section{The Saint Mary's Sexual Assault Referral Centre}

The study is based on the caseload of the Saint Mary's SARC, which provides services to complainants in sexual offences cases. This was the first SARC in the UK, founded in 1986, and is where Greater Manchester and Cheshire Police take complainants for support and preservation of forensic evidence. Most complainants come to the SARC via a police referral but they can also self-refer. As well as a venue for initial emotional support to the complainant the Saint Mary's SARC has the resources to perform forensic medical examinations (FME). Evidence gathered may be of use in a future court case should the complainant decide to go to court. Saint Mary's SARC has a unique service delivery model whereby it provides a comprehensive and co-ordinated forensic, counselling and aftercare service to children, women and men who have reported sexual assault or rape.

Complainants are also assigned an Independent Sexual Violence Advisor (ISVA) through the Saint Mary's SARC. The ISVAs are specialist professionals with a multi-faceted role, the key role is perhaps to support the complainant through the CJS. The ISVA will discuss court processes with the complainants including the special measures for giving evidence and will accompany the complainant at their pre-court visit and, if possible and wanted, be there while the complainant gives evidence. The ISVA can advocate on the c complainant's behalf to the CPS and police where necessary (Ryan, 2013). The pre-court visit also allows opportunity for the complainant to speak to court staff that may be available. 


\section{Method}

Adult complainants attending Saint Mary's SARC were surveyed between $25^{\text {th }}$ January 2016 and $31^{\text {st }}$ Oct 2017, regarding their choice of special measure, by their ISVA. The survey was completed prior to giving evidence in court, but after complainants had completed pre-court visits, where these were possible. The survey was piloted and after minor tweaks was successfully rolled out. From piloting the survey the authors were reassured that the brief nature of the survey and the questions asked did not over-burden complainants. Following this evaluation period the survey's use was discontinued. It is important to note that at Saint Mary's SARC, children and their carer's are also supported by ISVAs in court and they are also able to access special measures, however data on this study is based on adults only.

ISVAs were given training to ensure that bias was minimised before they provided the complainants with the surveys. The option of completing the form in private (returning it using a sealed envelope) was also offered. A mixed-methods survey design was selected to provide an over-arching view of the impact of special measures and answer the study questions without over-burdening complainants. The study had quantitative research questions: Which special measures are used in sexual offences trials? How often is each type used? Are they used in combination? The study also had qualitative research questions: What are the views of the complainants about special measures? How did they decide what special measures to request?

The survey comprised of just four questions (see Table 1).

<Insert Table 1 here $>$

Questions 1 and 2 were quantitatively analysed to produce descriptive statistics regarding the uptake of special measures for sexual offences trials supported by Saint Mary's SARC ISVAs. Questions 3 and 4 allowed for free-text responses of complainants perspectives which were subsequently thematically analysed.

As this survey was introduced to evaluate the newly introduced Saint Mary's SARC live link service, and only staff with Saint Mary's SARC contracts would see the raw data, Health Research Authority (HRA) advised that the project did not require review from an NHS ethics committee. 


\section{$\underline{\text { Results }}$}

A total of 72 surveys were gathered from adult participants over the 22 month study period. 11 surveys were excluded ( 2 duplicates, 3 did not provide enough information, 6 could not be verified) leaving a sample of 61 . This was a 35\% survey completion rate i.e. there were over 200 court cases supported by Saint Mary's SARC adult ISVAs over this time period so just over one in three complainants took part in this survey. For further context, in the year2017/8 there were 581 rape and sexual offence court cases in Greater Manchester, so this group of 61 complainants constitutes a small but significant sample of the whole (it is not possible to calculate the percentage of all cases as the numbers of complainants in each case is not known).

Table 2 shows that the majority of the 61 complainants in this study were mostly White British females aged between 18 and 55 years. This demographic data is not complete and also needs to be compared to the total sample of SARC cases, to give an idea about how representative the sample is. That said, in a wider sample of cases from the Saint Mary's SARC it can be said that there is more ethnic diversity.

<Insert Table 2 here>

Complainants in sexual offences cases have the opportunity to have their evidence-in-chief video-recorded. This survey did not investigate the take-up of video-recorded evidence. Further consideration will be given to including this in future work. The four options for obtaining further evidence through cross-examination in the Greater Manchester area are:

- Open court;

- In court with screens around complainant and use of screens in court;

- Live link from within the court building;

- Remote live link, from Saint Mary's SARC.

These are the special measures investigated in this small study. The team have discovered that combinations of special measures were not offered to complainants, although, as already noted, these should be possible.

For example use of a live link with the addition of screens to prevent the face of the complainant being seen by the defendant. This deserves further work and the discussion returns to this point.

<Insert Figure 1 here> 
Figure 1 shows that the majority of complainants viewed three or more options for giving evidence in court before reaching their decision. Complainants who had the opportunity to see most or all of the options for giving evidence found the process useful $(n=36,59.02 \%$; explicitly stated $n=17,27.87 \%$; implicitly stated $n=19$, 31.15\%). Screens were the most popular option for giving evidence in court (see Figure 2).

$<$ Insert Figure 2 here $>$

Reasons for choosing to give evidence in a given way were thematically analysed and grouped into the following three themes: 'Visibility', 'In the courtroom' and 'Use of live links'. This left a small group of 'Outlying reasons' and these are presented below. These categories were created by analysing free text responses and so respondents had often given more than one reason. Totals thereof exceed 61. All are presented visually (see Table 3) and discussed in turn below.

<Insert Table 3 here>

\section{$\underline{\text { Visibility }}$}

Visibility was the strongest theme that emerged from the analysis with not wanting to see or be seen acting as the most common influencers in complainants decision-making. The sense of embarrassment and (perhaps) shame at going into open court and being asked to speak about intimate behaviours is widely understood and contributed to the changes that allowed screens for adult complainants, placed around the complainant box (YJCEA 1999, s.23, discussed by Temkin, 2002, pp.318-319). Screens had previously been used in cases with child complainants (Ibid). This sample reinforces the importance of screens, whilst also raising some new insight into their use. What comes across clearly is that complainants are not all the same, they deserve choice in how they give evidence, in order to allow them to give their best.

Screens were by far the most popular form of special measure (72\%) amongst the complainants in this study. It is interesting to consider whether the ISVAs and other professionals who the complainant might meet would also be most comfortable with this form of adaptation. In other words, without further research it is difficult 
to be certain about how the complainants arrived at their decisions and who or what influenced those. That said it is also true that some of the comments below do give insight into some professional views.

In answering question 3 in the survey, complainants commented on not wanting to see the: defendant; defendant's supporters; public gallery and/or anyone in court.

"I wish I could have gone in open court but I know if I saw him I would get really angry."

"Felt I had nothing to hide but I did not want to see the man who had done this to me."

"My ex-partner, don't want to see him or his family."

These answers are interesting in terms of the range of issues they bring up. One reminds the reader of the complexity of the relationships which complainants in sexual offences cases have to negotiate (a former partner and his family as opposed to the persistent stereotype of the stranger assailant). In contrast, another complainant said simply:

"He is my brother so I've seen him a lot so didn't feel needed screens or videolink."

The comments above also show that complainants are not always choosing to remain invisible for shame, but to protect their feelings in other ways, simply not wanting to see him, or to avoid being too angry.

Complainants also reflected on not wanting to be seen by the defendant, defendant's supporters and/or the public gallery in person or on screens. Again, their reasons deserve some consideration. In particular the idea that getting upset should not be on display, particularly to the accused.

"I did not want the offender to see my face or see if I was getting upset."

"Did not want him to see me, he shouldn't get to see me. I especially don't want him to see me if I get upset."

"Didn't want anyone in the public gallery to see me - how I look as I am now."

These complainants are asserting a right to privacy. Conversely some complainants noted the contrary in their decision-making; wanting to see and be seen. Here the answers they gave show that they equate this choice with courage and even believe it might make a difference to the jury's response.

"Wanted the jury to see me as a real person, not sure they might see my body language over the video link." 
"I wanted to face the defendant... I was determined to go in open court."

The notion of being seen was clearly an important one for complainants in this group of cases and the conclusions that they reached regarding visibility differed. Another key theme was the wish to go to court and an underlying assumption that it is better to appear in person, if possible. Again, further research might help to unpick the extent to which these ideas are reinforced by the professionals that the complainants meet, prior to choosing how to give evidence. Previous research suggests that juries might not perceive the evidence differently via screen or in person, but perhaps this is not always what complainants are told. That said, this small study challenges received stereotypes of complainants hiding from the accused with two of the complainants clearly wanting to be there and be seen.

\section{In the courtroom}

The understanding that it was better to appear in person can also be seen in these comments:

"Want to be in court but not be seen."

"I felt like it would come across better if I was in court."

"Felt like it is more personal - people can see me better - see my body language which you don't get on screen. I don't feel like I'm hiding."

So the assumption here is that appearance via live link is somehow less convincing or persuasive than being in court, even with the use of screens. Other complainants were clear that they could not go to court, but the underlying notion that it would have been better to do so is still visible here:

"I suffer with very severe anxiety-depression and the thought of being in court was too much for me."

"Wouldn't go to court, too scary - my mental health wouldn't stand up to it."

The use of the screens, the most popular special measure, was often favoured due to the complainant feeling better able to evidence in court, and the feeling that by being in the physicality of the courtroom they were not hiding. Other important points made about screens related to having ISVA support nearby.

"Felt more comfortable with screens. Also my ISVA could come in court with me."

"I was made to feel better as my ISVA assured me she would be able to be there on the day." 
The ISVAs at Saint Mary's SARC report that they have sometimes been able to be with complainants in the live link room but that, at other times, this has been refused. Again, this is of concern as there does not appear to be a clear reason for this inconsistency, and this topic is raised again, later on. Finally, there was one comment noting a negative regarding the physicality of the screens.

"The screen felt too close in court room."

\section{Use of live links}

The live link technology was used far less often that screens, in this small study. Nevertheless, $25 \%(\mathrm{~N}=15)$ of the complainants used live link and the reasoning here is also interesting.

Clearly giving evidence from the SARC, a place which the complainant has visited before, might lead to a number of advantages. In this study, women said that positives of SARC live link included: feeling confident giving evidence in this way; relaxed atmosphere at SARC for giving evidence; ill health meant could not give evidence any other way; fear of defendant and his family.

"I was scared of him and his family I don't want to see him or anyone else and when I saw the link at Saint Mary's knew I would be best doing it here."

"Felt more confident giving evidence this way. Especially being away from court environment."

So the SARC offers a safe haven for some complainants who might not otherwise give evidence and, even where only a minority of cases use this technology, it is important if it means that more complainants are able to appear at trial. It would be interesting to be able to investigate this decision-making further. For example, did those who decided to appear in court give consideration to the thought that appearing from Saint Mary's SARC would entirely eradicate the risk of meeting with the defendant and his supporters? Clearly some complainants did think about this:

"The court was in a different location to where I live - I was scared if I go to court the family would follow me from court and something would happen."

Earlier research shows that complainants do meet up with or see the defendant in or around the court building (including in the canteen, in the toilets and outside the courtroom) if they attend court (Hamlyn, B. et al, 2004). Questions which could probe this further will be considered in designing any follow-on research. 
It would also be interesting to investigate the impact of giving evidence by remote live link on the sense of confidence of the complainants. If they could also know that screens were being used in court (so that the defendant could not see them) then this might impact on the uptake of live link and even potentially on the outcome of cases. Again, further investigation of all of this would be worthwhile.

However, there is an alternative view and where a complainant has not had a positive experience at the SARC, then returning there will not offer any comfort. In this study just one complainant said that they did not want to re-attend the SARC after having been there for the forensic medical examination.

The other live link choice is to give evidence from within the court building. The room set aside for this, within the local court, is rather small and this led to a number of negative comments.

"I couldn't even bring myself to the videolink room. Felt very claustrophobic and my ISVA would not be there." As mentioned above, the issue of having the ISVA in the live link room is one that this discussion returns to. In the meantime, other interesting issues were raised in terms of live link. For example, one complainant needed an interpreter:

"Did not want to go into court. Video link refused due to need for BSL interpreter and intermediary."

Another also wanted the ISVA close by and found the television link disconcerting:

"Wanted to have my ISVA close for support - felt disconnected when I looked at videolink."

Finally, the sheer size of the screen was difficult for one complainant:

"I did not like the massive screen in the videolink room - made me feel overwhelmed."

In general then there were a range of issues raised about the use of the televised link which the research team recognise deserve further exploration.

\section{Other influences}

The research does also illustrate the role of professionals in making these decisions about giving evidence. As noted above, one complainant said simply:

"The police officer just said I was doing it via video link." 
And clearly this is quite problematic. Another had a similar story to tell:

"I had addressed this with the police - they thought it was best I gave evidence that way... I hadn't really had opportunity to talk to anyone else."

In other cases, where there are multiple complainants, the decision may appear to be made for the complainant, in a different way:

"My other family members were giving evidence this way."

Whilst for some complainants, this is not a new process:

"Have done it before, feel relaxed at Saint Mary's and I know ISVA well."

In all then, the comments of the complainants in this sample demonstrate the diversity of types of cases and the complexity of the decision-making process with regards to giving evidence.

\section{Discussion}

This study provides new insight into the views of those who appear as key complainants in sexual offences cases. The sample in this study is limited in terms of size and diversity. A number of other issues with the current research have already been noted and it is the team's intention to undertake further work on this, in the future. The key findings of this study are now recapped under the themes of making choices and being seen before some conclusions are drawn.

\section{Making choices}

In general this study shows that it was helpful to complainants to have the opportunity to visit the court and consider special measures, before giving evidence. Burton et al's (2006) research suggested that "In many cases the CPS applied for special measures at a late stage, including on the day of the trial. This was accepted practice in relation to measures such as screens, clearing the public gallery and the removal of wigs and gowns. This ignored the value to VIWs of knowing what will happen in court well in advance of the hearing." Whilst this is not standard practice in Manchester this study has highlighted some cases where the choice of special measure was not made by the complainant and where the choice was not offered in a timely manner. 
Within this study, an initial attempt was made to survey the complainants again, after they had given evidence in court. In the event it transpired that they tended to replicate their answers and so this second survey was discontinued. However, it was also interesting to note that the complainants tended to come out of court believing that they had made the right decision with regards to giving evidence. This allows some increased confidence in the systems that are present, notwithstanding the comments already made. In a future project the team would want to qualitatively investigate the views of complainants once the outcome of the case was known, to see what impact that might make.

\section{Being seen}

The issue of visibility was of importance to many of the complainants in this study. Screens remain the most popular category of special measure, but it is not clear that all complainants are making a free choice about using screens and it is apparent that some (for example the hearing-impaired complainant) have a choice that is limited by the court. Some are simply being told by police officers what to use and it is less clear whether others are also influenced by the views of others. All of this is worthy of further investigation.

Some complainants indicated that they did not want to go to court and did not want to be seen. As identified by this study there were no cases where combination of special measures were provided to complainants despite the CPS website suggesting this should be a feasible option. Moreover, Saint Mary's SARC ISVAs attest that combination of special measures is not routinely available in Greater Manchester. This suggests that existing policy is not being implemented in current practice and ought to be pursued in future work. The research team aims to discuss this with police and courtroom staff locally but also to highlight this with colleagues in other parts of the country. It is interesting to ponder the comment from Burton et al above. If the special measures are only chosen at the last minute, perhaps that mitigates against combinations which might also be inconvenient for staff within the courtrooms.

Some of the complainants were clear that they wanted to be physically inside the courtroom to give evidence and that their evidence would be more compelling in a number of ways. It would be interesting to investigate where these ideas came from. Ellison and Munro's work, already discussed, suggests that (mock) jurors might not see any real difference between remote and live evidence, so the notion that being in court makes a big impact could be misplaced. 
It is important to emphasise that while the majority of complainants do not want to see or be seen, for some it is extremely important that they are seen. It is therefore essential that complainants are offered all available special measures.

\section{Conclusions}

New evidence provided by this study gives fresh insight into complainants' decision-making process and the value of the various special measures. This will inform: advice to complainants; training for professionals and recommendations for the development of future services regarding special measures with implications for both policy and practice at a national level. In addition, the evidence will also be available for use by legal professionals in other jurisdictions, considering how to improve the experience of complainants in sexual offence cases.

There is some indication of problems with police practice in some cases, where complainants were simply told how they were giving evidence. It is not known whether there are actually other instances where this happens and where the complainant simply withdraws their evidence. However, this points to a clear training need. Further research will also investigate professionals' views and their impact on complainant decision-making. More detailed questions on what information c complainants had, when they made their decisions might also help to unpick their views.

This work began with the aim of investigating the use of the remote live link at Saint Mary's SARC. It was discovered that this is used successfully in a small number of cases involving adult complainant. However the study has also uncovered reasons why the link is not used more widely, particularly where complainants actually wanted to use a combination of measures. It was clear that some of the complainants might have used the live link, if they could be sure that the defendant could not see their face, on the screen in the courtroom. It is not known what impact this possibility might have on attrition or on outcomes. However, ISVAs report that screens and live link are not generally permitted in combination. ISVAs note that courts are set up differently and often it is not even logistically possible to combine screens and video links. For example, in some cases, where there are large video screens it would not be possible for the judge and jury to see the complainant but not the defendant or public gallery. Clearly all of this needs to be investigated further and 
discussed with court officials. Previous research notes that the judges generally allow what is asked for in terms of special measures. Burton et al concluded: "Judges generally granted applications, and trial judges very rarely disagreed with decisions made in earlier stages of their cases." Burton, M., Evans, R. \& Sanders, A. (2006) p.vii).

Another concern was that the complainants were given the impression that they had to choose between giving evidence in court, with their ISVA there as supporter or giving evidence by live link, without that support. This was particularly stark where one complainant needed a BSL interpreter to give evidence, and this was not permitted in combination with live link. Again, there do not appear to be reasons for this and it warrants further work. This study did not look at the uptake of video-recorded evidence and future work will also give consideration to asking about this.

The research team will continue to investigate all of the issues raised in this study and to raise awareness around the problems with implementation of special measures. Women's testimony about sexual offences clearly shows that rape is a crime where autonomy over one's body is taken away. The guiding principle for the CJS and its practitioners should always be to give back autonomy, as much as is possible. To date, this initial research shows that there is plenty of room for improvement in this regard. The article began by mentioning the ongoing struggle of taking cases right through the CJW to court. It has long been clear that a range of issues are combined in making up this problem of attrition and this work highlights some aspects of just one part of that story.

\section{Acknowledgements}

The authors want like to thank the survivors of sexual offences who were kind enough to share their views on special measures. Thanks also to the staff at Saint Mary's SARC who made this work possible, in particular the Adult ISVAs for their role in collecting the survey data. Thanks are also owed to Mathew Gray at The University of Law who organised a literature review on special measures which supported this project. 


\section{References}

Burton, M.; Evans, R., \& Sanders, A. (2006) Are special measures for vulnerable and intimidated complainants working? Evidence from the Criminal Justice Agencies. On-line Report 01/06. Home Office: London.

Burton, M.; Evans, R. \& Sanders, A. (2007) Vulnerable and Intimidated Complainants and the Adversarial Process in England and Wales, The International Journal of Evidence and Proof, 11(1), pp.1-23.

Cook, K. (2011) 'Rape Investigation and Prosecution: Stuck in the Mud?', Journal of Sexual Aggression, 17(3), pp. 250-262.

Ellison, L. and Munro, V. (2014) 'A “Special” Delivery? Exploring the Impact of Screens, Live-Links and VideoRecorded Evidence on Mock Juror Deliberation in Rape Trials", Social Legal Studies, 23.1, pp. 3-29.

Fairclough, S. (2018). Speaking up for Injustice: Reconsidering the provision of special measures through the lens of inequality, Criminal Law Review (1) pp. 4-19.

Government, U. (2017) Criminal Justice Statistics Quarterly, Gov.UK. Available at:

https://www.gov.uk/government/statistics/criminal-justice-system-statistics-quarterly-december-2017.

Hall, M. (2007) The Use and Abuse of Special Measures: Giving Victims the Choice? jounral of Scandanavian Studies in Criminology and Crime Prevention, 8(1) pp.33-53.

Hamlyn B., Phelps A., Turtle J. \& Sattar G. (2004) Are Special Measures Working? Evidence from Surveys of Vulnerable and Intimated Complainants (Study 283). Home Office Research, Development and Statistics Directorate, London.

Jones, H. and Cook, K. (2008) Rape Crisis: Responding to Sexual Violence. Russell House.

McNamee, H., Molyneaux, F. and Geraghty, T. (2012) Key Stakeholder Evaluation of NSPCC Young Complainant Service Remote Live Link (Foyle). Northern Ireland: NSPCC.

Ryan B, (2013) 'The Work of a Sexual Assault Referral Centre' in: J Pritchard, Good Practice in Promoting Recovery and Healing for Abused Adults, Jessica Kingsley Publishers, 62-81.

Sexual Offences Appendix tables (2018) ONS Website. Available at:

https://www.ons.gov.uk/peoplepopulationandcommunity/crimeandjustice/bulletins/crimeinenglandandwales 
/yearendingdecember2017.

Special Measures / The Crown Prosecution Service (2017). Available at: https://www.cps.gov.uk/legalguidance/special-measures (Accessed: 5 September 2018).

Temkin, J. (2002) Rape and the Legal Process. 2nd edn. OUP. 
Table 1: Survey questions answered by complainants before giving evidence in court

1. What option have you chosen for giving evidence in court?

2. What options did you view before reaching a decision on how to give evidence in court?

3. What were your reasons for choosing to give evidence in this way?

4. Is there anything else you would like to comment on about your experience of choosing an option for giving evidence in court?

Table 2: Partial demographic profile of complainants that completed the survey ${ }^{1}$

$N=61 \quad$ \% of group

\begin{tabular}{lcc}
\hline $18-25$ & 23 & $37.70 \%$ \\
$26-35$ & 17 & $27.87 \%$ \\
$36-55$ & 20 & $32.79 \%$ \\
$55+$ & 1 & $1.64 \%$
\end{tabular}

\begin{tabular}{lcc}
\hline Female & 58 & $95.08 \%$ \\
Male & 2 & $3.28 \%^{2}$ \\
Non-Binary & 1 & $1.64 \%^{3}$
\end{tabular}

Other

\footnotetext{
${ }^{1}$ Unfortunately no data is available on the sexuality and/or disability of the witnesses. This would be an important consideration in future work.

${ }^{2}$ Both gave evidence using screens.

${ }^{3}$ Gave evidence via the SARC live link.
} 
Table 3: Complainants' reasons when choosing how to give evidence

\begin{tabular}{|c|c|c|}
\hline Major Category & Minor category & Sub-category \\
\hline \multirow[t]{14}{*}{ Visibility (49) } & \multirow[t]{5}{*}{ Not wanting to see (24) } & Do not want to see him [defendant] (14) \\
\hline & & Do not want to see anyone in court (4) \\
\hline & & Do not want to see his [defendant's] family / supporters (4) \\
\hline & & I would get angry if I saw defendant (1) \\
\hline & & Do not want to see anyone in public gallery(1) \\
\hline & \multirow{6}{*}{$\begin{array}{l}\text { Do not want to be seen by } \\
\text { person / people (19) }\end{array}$} & Do not want to be seen on video screens (6) \\
\hline & & Do not want defendant to see me (6) \\
\hline & & Do not want to be seen (2) \\
\hline & & Do not want defendant to see me getting upset (2) \\
\hline & & Do not want public gallery to see me (2) \\
\hline & & Do not want defendant's supporters to see me (1) \\
\hline & Wanting to see (1) & Wanted to face the defendant (1) \\
\hline & \multirow[t]{2}{*}{ Wanting to be seen (5) } & Jury can see me and my body language (4) \\
\hline & & I wonder if he [defendant] saw me if he would plead guilty (1) \\
\hline \multirow{11}{*}{$\begin{array}{l}\text { In the } \\
\text { courtroom (31) }\end{array}$} & \multirow[t]{3}{*}{ Positives of courtroom (5) } & Want to be in court (3) \\
\hline & & Felt it would come across better in court (1) \\
\hline & & Comfortable in court (1) \\
\hline & \multirow{3}{*}{$\begin{array}{l}\text { Negatives of courtroom } \\
\text { (9) }\end{array}$} & Do not want to go into courtroom (6) \\
\hline & & Mental health meant court was too much (2) \\
\hline & & Do not wish to see courtroom (1) \\
\hline & \multirow[t]{4}{*}{ Positives of screens (16) } & Felt better giving evidence in court behind a screen (7) \\
\hline & & Want ISVA / Saint Mary's SARC support close (6) \\
\hline & & I have not done anything wrong / I have nothing to hide (2) \\
\hline & & I do not feel like I am hiding (1) \\
\hline & Negatives of screens (1) & Screens in courtroom too close (1) \\
\hline
\end{tabular}




\begin{tabular}{|c|c|c|}
\hline \multirow[t]{14}{*}{ Videolinks (27) } & \multirow[t]{5}{*}{ Positives of SARC (7) } & Felt better when I had seen it (2) \\
\hline & & Relaxed atmosphere (2) \\
\hline & & III health would not allow giving evidence another way (1) \\
\hline & & Scared of him and his family (1) \\
\hline & & Felt confident giving evidence this way (1) \\
\hline & Negatives of SARC (1) & $\begin{array}{l}\text { Do not want to attend SARC after Forensic Medical } \\
\text { Examination (1) }\end{array}$ \\
\hline & Positives of videolink (1) & Do not want to be followed from court (1) \\
\hline & Negatives of videolink (18) & Videolink rooms made me feel claustrophobic (8) \\
\hline & & Court videolink room too small (3) \\
\hline & & Do not like videolink room (2) \\
\hline & & Do not want videolink (2) \\
\hline & & Cannot have British Sign Language interpreter (1) \\
\hline & & Felt disconnected when I looked at videolink (1) \\
\hline & & Do not like videolink screen - felt overwhelmed (1) \\
\hline Outlying & Problematic Police & Not fully informed (1) \\
\hline reasons (7) & involvement (3) & Police advised me to give evidence this way (1) \\
\hline & & Not given a choice (1) \\
\hline & Other (4) & Other family members gave evidence this way (1) \\
\hline & & I have done it before (1) \\
\hline & & Location of court (1) \\
\hline & & Relation to defendant (1) \\
\hline
\end{tabular}


Figure 1: Histogram of number of options viewed when choosing how to give evidence

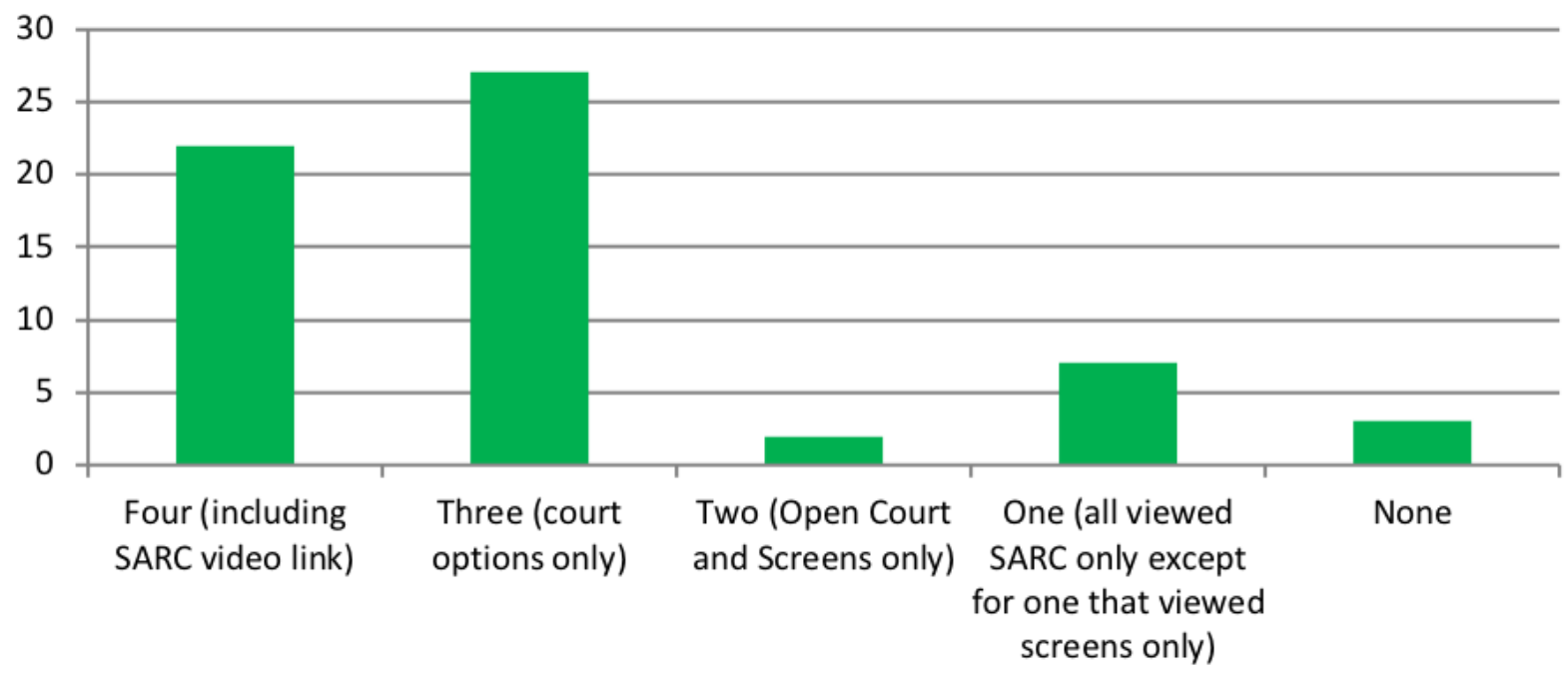

Figure 2: Histogram of methods chosen for giving evidence

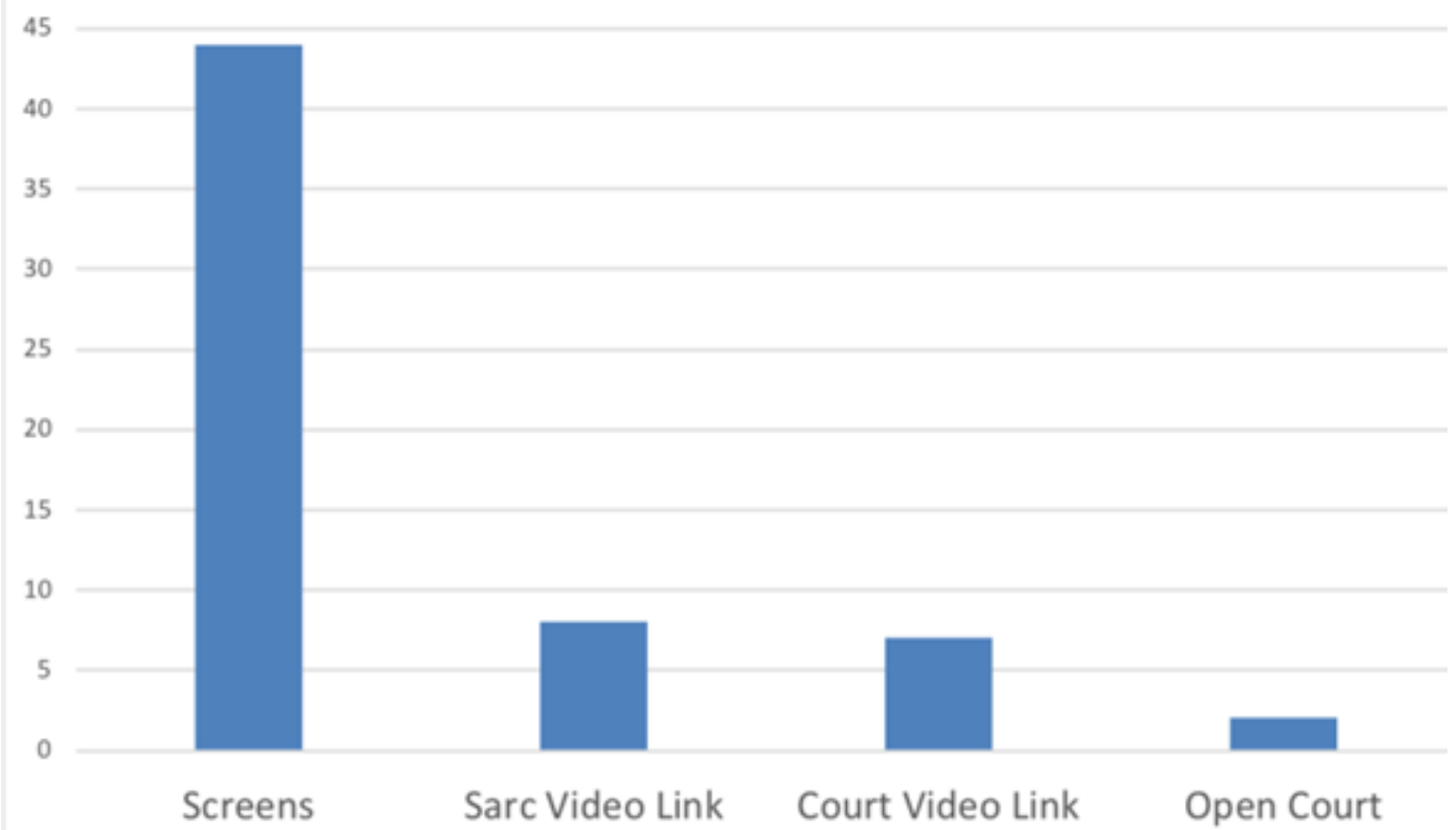

